\title{
Dominant X linked subcortical laminar heterotopia and lissencephaly syndrome (XSCLH/LIS): evidence for the occurrence of mutation in males and mapping of a potential locus in Xq22
}

\author{
INSERM U129-ICGM, \\ Faculté de Médecine \\ Cochin, 24 rue du \\ Faubourg \\ Saint-Jacques, 75014 \\ Paris, France \\ $\mathrm{V}$ des Portes \\ P Billuart \\ A Carrie \\ T Bienvenu \\ M C Vinet \\ C Beldjord \\ A Kahn \\ J Chelly
}

Service de

Neuropédiatrie,

Hôpital R Poincaré,

Garches, France

J-M Pinard

Service de Neurologie, Hôpital la Ménard, Fort de France, Martinique

D Smadja

Service de

Neuropédiatrie, American Memorial Hospital, Reims, France

$\mathrm{J}$ Motte

Service de

Neuropédiatrie,

Hôpital St Vincent de

Paul, Paris, France

M-L Moutard

I Desguerre

$G$ Ponsot

O Dulac

INSERM U384, Faculté de Médecine,

Clermont-Ferrand,

France

O Boespflüg-Tanguy

GIS INFOBIOGEN, Villejuif, France

L Bachner

Correspondence to: Dr des Portes.

Received 12 July 1996 Revised version accepted for publication 10 October 1996

V des Portes, J M Pinard, D Smadja, J Motte, O Boespflüg-Tanguy, M L Moutard, I Desguerre, P Billuart, A Carrie, T Bienvenu, M C Vinet, L Bachner, C Beldjord, O Dulac, A Kahn, G Ponsot, J Chelly

\section{Abstract}

$\mathrm{X}$ linked subcortical laminar heterotopia and lissencephaly syndrome (XSCLH/ LIS) is an intriguing disorder of cortical development, which causes classical lissencephaly with severe mental retardation and epilepsy in hemizygous males, and subcortical laminar heterotopia (SCLH) associated with milder mental retardation and epilepsy in heterozygous females.

Here we report an exclusion mapping study carried out in three unrelated previously described families in which males are affected with lissencephaly and females with SCLH, using $\mathbf{3 8}$ microsatellite markers evenly distributed on the $X$ chromosome. Most of the $X$ chromosome was excluded and potential intervals of assignment in Xq22.3-q23 or in Xq27 are reported. Although the number of informative meioses did not allow a decision between these two loci, it is worth noting that the former interval is compatible with the mapping of a breakpoint involved in a de novo $X$;autosomal balanced translocation $46, X X, t(X ; 2)(q 22 ; p 25)$ previously described in a female with classical lissencephaly. In addition, haplotype inheritance in two families showed a grandpaternal origin of the mutation and suggested in one family the presence of mosaicism in germline cells of normal transmitting males.

$(\mathcal{F}$ Med Genet 1997;34:177-183)

Keywords: lissencephaly; subcortical laminar heterotopia; $\mathrm{X}$ inheritance.

Malformations of cortical development are an important cause of mental retardation and epilepsy. The recent widespread clinical use of magnetic resonance imaging (MRI) has enhanced the recognition and classification of this large and heterogeneous group of cortical dysgenesis, which can result from a failure of proliferation, migration, or organisation of neuronal and glial cells in the developing cortex. ${ }^{1}$ Cortical dysgenesis such as lissencephaly and subcortical laminar heterotopia (SCLH), also called band heterotopia or double cortex, are frequently if not always of genetic origin. Subcortical laminar heterotopia (SCLH) consists of bilateral extensive plates of heterotopic grey matter located between the cortex and the cerebral ventricles. Clinical manifestations are mainly epilepsy and mental retardation. ${ }^{2}$ The relative thickness of the heterotopic band correlates with the phenotype, as patients with thicker bands have more severe mental retardation and seizures. ${ }^{13}$ Furthermore, various thicknesses of SCLH may be observed in the same family." A "forme fruste" of SCLH consisting of bilateral and symmetrical bands with a regional distribution has been described. ${ }^{5}$ Lissencephaly, also called agyriapachygyria, is defined by the absence or a decrease of surface convolutions associated with a disorganisation of the layers of the cortex. The main clinical features associated with lissencephaly are profound mental retardation and epilepsy with many types of seizure. ${ }^{6}$ Various types of lissencephaly have been described; type I or "classical" lissencephaly includes both the Miller-Dieker syndrome (MDS), which comprises lissencephaly and a characteristic facial dysmorphism, and isolated lissencephaly sequence (ILS) without the striking facial appearance. ${ }^{7}$ Type II lissencephaly mainly includes the Walker-Warburg syndrome, which consists of lissencephaly, hydrocephalus, cerebellar malformation, and retinal dysplasia. ${ }^{8}$

Cytogenetic and molecular investigations have allowed the detection of deletions at 17 p13.3 involving the LIS-1 gene in most cases of Miller-Dieker syndrome (MDS) and several cases of isolated lissencephaly sequence (ILS)..$^{9}$ Segregation analyses of families 
A

Family 1

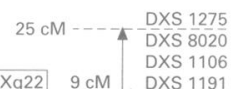

$\begin{array}{lll}\times \mathrm{X} 22 & \mathrm{cM} & \text { DXS } 1106 \\ \text { DXS } 1191\end{array}$

$33 \mathrm{cM} \ldots$ DXS 1072

$33 \mathrm{cM}-$ DXS 1062

DXS 8106

Xq27 $19 \mathrm{cM}$ DXS 8073

DXS 8084

DXS 1215

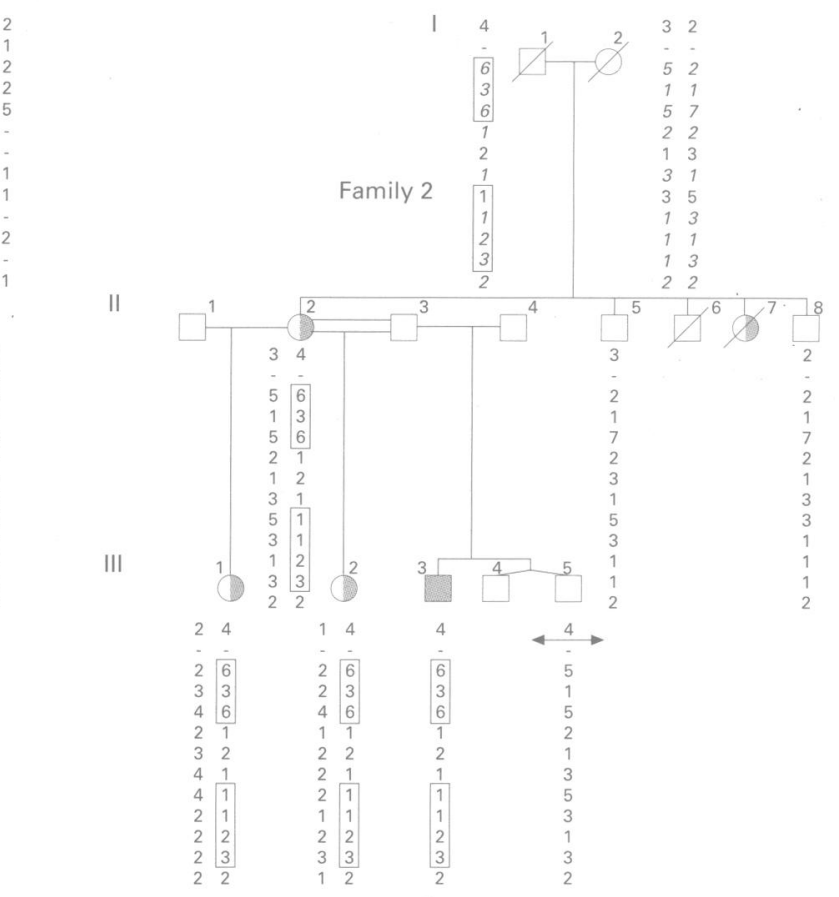

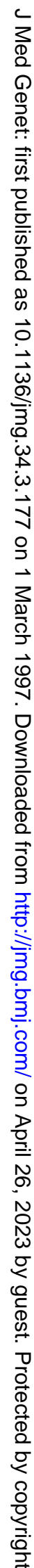

Figure 1 (A) Pedigrees of the three unrelated XHLSC/LIS families with haplotypes corresponding to the regions of interest. In family 2, haplotypes of subjects $I .1$ and I 2 are deduced from alleles of II.2, II.5, and II. 8. (B) Four axial MRI images performed in several affected subjects, showing the wide range of thickness and extension of subcortical laminar heterotopia in females (left hand pair) and the continuum from pachygyria to complete agyria range of thickness and extension of subcortical laminar heterotopia in females (left hand pair) and the continuum from pachygyria to complete agyria
within the lissencephaly entity in males (right hand pair). (From left) (1) Thin layer of heterotopic grey matter in both frontal lobes in patient II.2, family within the lissencephaly entity in males (right hand pair). (From left) (1) Thin layer of heterotopic grey matter in both frontal lobes in patient II.2, family
2. (2) Extended band of thick heterotopic grey matter in patient III. 1, family 2. (3) Generalised agyria in patient II.3, family 1. (4) Smooth cortex with 2. (2) Extended band of thick heterotopic grey matter in patient IIt. , family 2. (3) Generalised agy
bilateral frontal agyria and pachygyria of the parietal and occipital lobes in patient III. 3 , family 2 . 
Table 1 Pairwise lod scores performed with a full penetrance on unambiguous subjects between XSCLH/LIS syndrome and Généthon polymorphic markers spanning Xq22 to Xq28 regions. For each marker, the first line corresponds to the first linkage analysis using a model of an $X$ linked dominant disease with complete penetrance (the phenotypes of the grandfather and grandmother in family 2 were set as healthy and unknown respectively); the second line corresponds to the same model taking into account the inheritance from the grandfather of the abnormal haplotype.

\begin{tabular}{|c|c|c|c|c|c|c|c|c|c|c|}
\hline \multirow[b]{2}{*}{ Locus } & \multirow[b]{2}{*}{ Location } & \multicolumn{9}{|c|}{ Lod score $(Z)$ at recombination frequencies $(\theta)$} \\
\hline & & 0.0 & 0.01 & 0.05 & 0.1 & 0.2 & 0.3 & 0.4 & $\theta \max$ & $Z \max$ \\
\hline \multirow[t]{2}{*}{ DXS8020 } & $\mathrm{Xq} 22.2$ & $-\infty$ & -1.4 & -0.7 & -0.4 & -0.2 & -0.1 & 0.0 & 0.5 & 0.0 \\
\hline & & $-\infty$ & -1.4 & -0.7 & -0.4 & -0.2 & -0.1 & 0.0 & 0.5 & 0.0 \\
\hline \multirow[t]{2}{*}{ DXS1106 } & $\mathrm{Xq} 22.2$ & 1.81 & 1.77 & 1.61 & 1.40 & 0.97 & 0.53 & 0.16 & 0.0 & 1.81 \\
\hline & & 1.20 & 1.18 & 1.07 & 0.93 & 0.65 & 0.36 & 0.11 & 0.0 & 1.20 \\
\hline \multirow[t]{2}{*}{ DXS1191 } & $\mathrm{Xq} 22.2$ & 1.45 & 1.41 & 1.21 & 0.96 & 0.45 & 0.0 & -0.2 & 0.0 & 1.45 \\
\hline & & 1.75 & 1.72 & 1.58 & 1.40 & 1.03 & 0.66 & 0.31 & 0.0 & 1.75 \\
\hline \multirow[t]{2}{*}{ DXS1210 } & Xq22.3 & 1.20 & 1.17 & 1.05 & 0.89 & 0.58 & 0.30 & 0.08 & 0.0 & 1.20 \\
\hline & & 0.60 & 0.58 & 0.52 & 0.43 & 0.27 & 0.13 & 0.03 & 0.0 & 0.60 \\
\hline \multirow[t]{2}{*}{ DXS1059 } & $\mathrm{Xq} 23$ & 2.11 & 2.06 & 1.86 & 1.61 & 1.10 & 0.60 & 0.18 & 0.0 & 2.11 \\
\hline & & 1.50 & 1.47 & 1.33 & 1.15 & 0.78 & 0.43 & 0.13 & 0.0 & 1.50 \\
\hline \multirow{2}{*}{ DXS1072 } & $\mathrm{Xq} 23$ & -2.4 & -0.8 & -0.2 & -0.1 & -0.1 & -0.2 & -0.2 & 0.13 & -0.1 \\
\hline & & -2.2 & -0.6 & -0.1 & 0.26 & 0.36 & 0.31 & 0.18 & 0.2 & 0.36 \\
\hline \multirow[t]{2}{*}{ DXS8088 } & $\mathrm{Xq} 23$ & -3.0 & -1.4 & -0.7 & -0.4 & -0.2 & -0.1 & 0.0 & 0.5 & 0.0 \\
\hline & & -3.0 & -1.4 & -0.7 & -0.4 & -0.2 & -0.1 & 0.0 & 0.5 & 0.0 \\
\hline \multirow[t]{2}{*}{ DXS1220 } & $\mathrm{Xq} 24$ & -2.7 & -1.1 & -0.4 & -0.2 & -0.1 & -0.01 & 0.0 & 0.42 & 0.0 \\
\hline & & -2.7 & -1.1 & -0.4 & -0.2 & -0.1 & -0.01 & 0.0 & 0.42 & 0.0 \\
\hline \multirow[t]{2}{*}{ DXS1047 } & Xq25 & -1.2 & 0.38 & 0.89 & 0.96 & 0.78 & 0.46 & 0.14 & 0.09 & 0.96 \\
\hline & & -1.8 & -0.2 & 0.35 & 0.49 & 0.46 & 0.29 & 0.09 & 0.13 & 0.50 \\
\hline \multirow[t]{2}{*}{ DXS1062 } & Xq26.2 & $-\infty$ & -9.6 & -5.4 & -3.7 & -2 & -1 & -0.4 & 0.5 & 0.0 \\
\hline & & -1.80 & -0.21 & 0.40 & 0.58 & 0.62 & 0.51 & 0.30 & 0.17 & 0.63 \\
\hline \multirow[t]{2}{*}{ DXS1227 } & $\mathrm{Xq} 27.1$ & $-\infty$ & -1.6 & -0.4 & 0.05 & 0.26 & 0.21 & 0.08 & 0.2 & 0.26 \\
\hline & & -1.8 & -0.2 & 0.35 & 0.5 & 0.46 & 0.29 & 0.09 & 0.13 & 0.50 \\
\hline \multirow[t]{2}{*}{ DXS8106 } & $\mathrm{Xq} 27.2$ & $-\infty$ & -7.6 & -4.2 & -2.8 & -1.5 & -0.8 & -0.4 & 0.5 & 0.0 \\
\hline & & 1.81 & 1.77 & 1.63 & 1.45 & 1.08 & 0.71 & 0.35 & 0.0 & 1.81 \\
\hline \multirow[t]{2}{*}{ DXS8073 } & $\mathrm{Xq} 27.2$ & $-\infty$ & -0.2 & 0.35 & 0.49 & 0.46 & 0.29 & 0.09 & 0.13 & 0.50 \\
\hline & & 1.20 & 1.18 & 1.07 & 0.93 & 0.65 & 0.36 & 0.11 & 0.0 & 1.20 \\
\hline \multirow[t]{2}{*}{ DXS8084 } & $\mathrm{Xq} 27.2$ & 1.45 & 1.41 & 1.21 & 0.96 & 0.45 & 0.0 & -0.2 & 0.0 & 1.45 \\
\hline & & 1.75 & 1.72 & 1.58 & 1.40 & 1.03 & 0.66 & 0.31 & 0.0 & 1.75 \\
\hline \multirow[t]{2}{*}{ DXS1215 } & $\mathrm{Xq} 28$ & -3.2 & -1.6 & -0.9 & -0.6 & -0.3 & -0.1 & 0.0 & 0.5 & 0.0 \\
\hline & & -3 & -1.4 & -0.7 & -0.4 & -0.2 & -0.1 & 0.0 & 0.5 & 0.0 \\
\hline
\end{tabular}

affected with Walker-Warburg syndrome showed autosomal recessive inheritance of this disorder. ${ }^{8}$ Recently, data which support the presence of $\mathrm{X}$ linked cortical dysgenesis were recognised. At least two distinct $\mathrm{X}$ linked disorders are known: (1) bilateral periventricular nodular heterotopia (BPNH) results in most cases in a mild phenotype consisting of epilepsy with normal intelligence in females, and a more severe phenotype with prenatal lethality or severe mental retardation in males, ${ }^{112}$ and has been mapped to $\mathrm{Xq} 28$ between DXS1113 and the telomere ${ }^{13}$; (2) X linked subcortical laminar heterotopia and lissencephaly syndrome (XSCLH/LIS), which consists of classical lissencephaly in hemizygous males and subcortical laminar heterotopia in heterozygous females, ${ }^{4}$ was delineated as a distinct $\mathrm{X}$ linked genetic syndrome only recently on the basis of three converging observations. ${ }^{414}{ }^{15}$ These were (1) a significant and striking skewing of the sex ratio towards females among sporadic patients with SCLH, ${ }^{14}{ }^{16}$ (2) identification of several multiplex families in which lissencephaly is only observed in males and SCLH is observed in females, ${ }^{41415}$ and (3) detection of a de novo balanced X;autosome translocation in a female with classical lissencephaly. ${ }^{7}$ However, so far, no linkage analysis data have been reported that can confirm and sublocalise the locus involved on the $\mathrm{X}$ chromosome.

In this paper, we report the first linkage study of XSCLH/LIS syndrome carried out in three unrelated families. Most of the X chromosome was excluded and a potential linkage with markers in Xq22.3-23 and Xq27 was found. Moreover, chromosomes carrying the mutated gene are transmitted by unaffected males, suggesting a skewed occurrence of mutations in male germline cells.

\section{Patients and methods}

FAMILY REPORT

We studied three previously described families affected with XSCLH/LIS syndrome, one from metropolitan France, ${ }^{4}$ one of Italian ancestry, ${ }^{4}$ and one from Guadeloupe. ${ }^{15}$ The phenotype of each family member and routine MRI or CT scans were checked by the same paediatric neurologist. Observation of relevant common clinical and radiological criteria (see Results section) indicated that these three families are affected with the same disease. Each family member was included in the genetic study after obtaining informed consent.

\section{Family 1}

Family 1 included three brothers of nonconsanguineous parents (fig 1A). The mother (I.2) has had epilepsy since the age of 11 years. MRI shows a thin bifrontal layer of heterotopic grey matter. The cortex seems to be normal. The youngest son (II.3) is 12 years old and has several malformations including microcephaly, hypertelorism, cleft lip and palate, abnormal palmar creases, and bilateral talus valgus. Mental development and growth are severely retarded without any visual contact and with axial hypotonia, bilateral pyramidal signs, nystagmus, strabismus, and refractory epilepsy. Scoliosis is associated with T12 hemivertebra and spina bifida occulta. MRI exhibits generalised agyria (fig 1B). The karyotype, including thorough analysis of chromosome 17, was normal. 


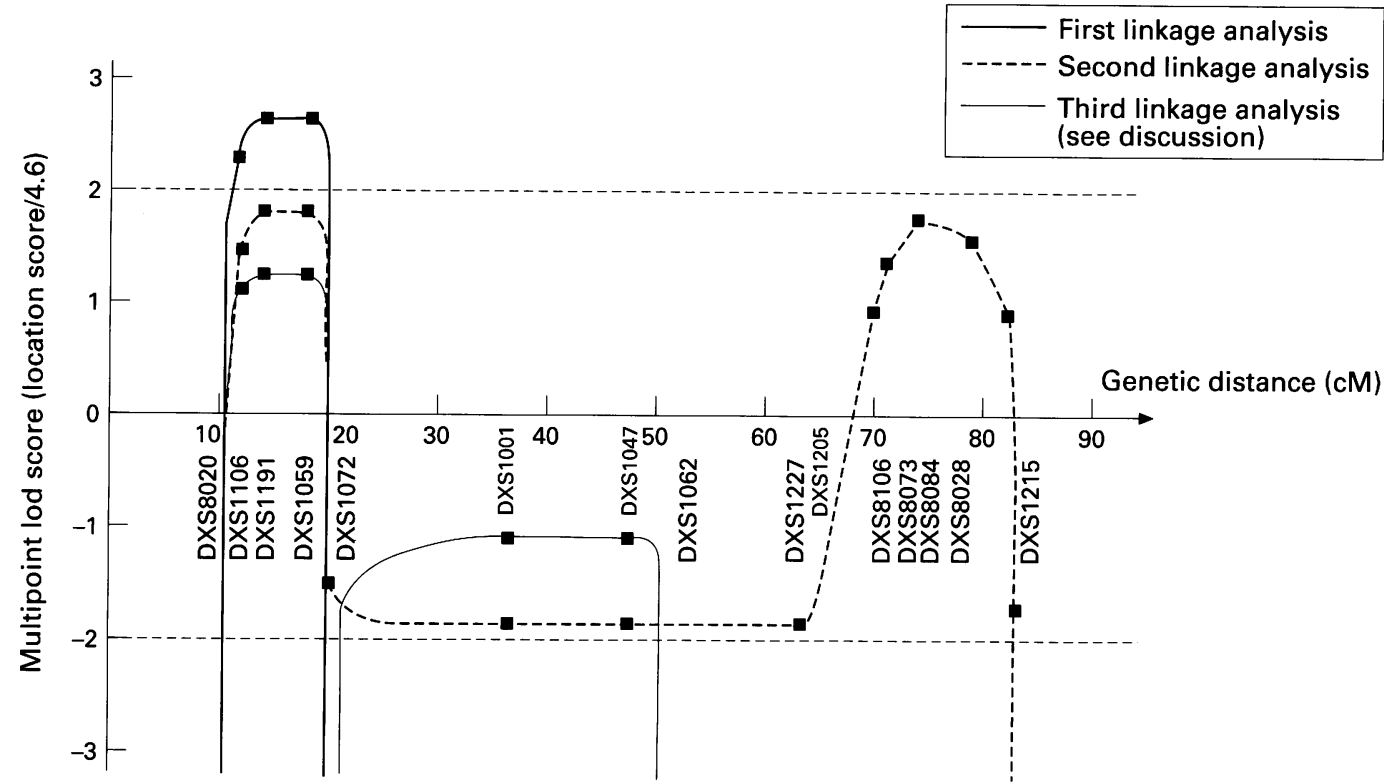

Figure 2 Multipoint lod score data from three different linkage analyses between XHLSC/LIS syndrome and different markers from Xq22 to Xq27. For the first and second linkage analyses, only unambiguously affected subjects were scored with complete penetrance; the grandfather's phenotype in family 2 was taken as healthy in the first linkage analysis and as an obligate carrier in the second one. The third analysis (data reported in the discussion) was performed with an incomplete penetrance, according to the model proposed in fig 3. All available subjects in the three families were scored for the linkage analysis, including atypical forms (II.10 and III.8) in the extended family 3.

\section{Family 2}

Family 2 included five affected subjects (fig 1 A). No epilepsy or mental retardation was reported in the grandfather; the grandmother was clinically healthy, but no brain imagery was

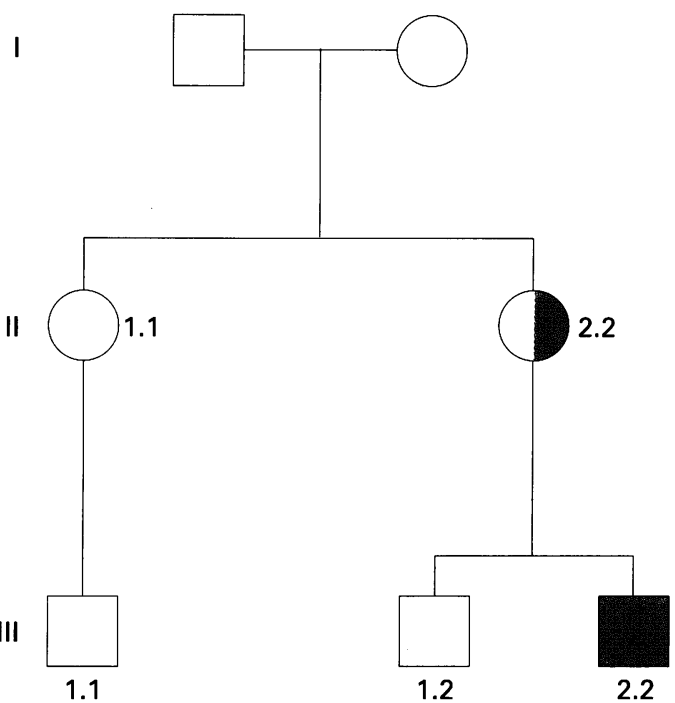

Figure 3 Genetic model with incomplete penetrance proposed for XHLSC/LIS syndrome. In this model, we assumed the grandfathers to be obligate transmitters and an incomplete penetrance for healthy carriers (in accordance with haplotypes and disease segregation in family 2 and extended family 3). Unaffected subjects are assigned to one of the two liability classes, on the basis of their mother's status, as described below. Sons of symptomatic females were assigned as impossible healthy carriers (penetrance $=1$ ) and children born to healthy mothers were considered as possible healthy carriers (penetrance $=0.8$ ). Each subject is coded with two numbers. The first number defines the phenotypic status: $1=$ unaffected subjects, $2=$ affected subjects. The second number determines the penetrance class for unaffected subjects, who are assigned to one of the two liability classes on the basis of their mother's status. Gen penetrance was defined as follows. Class 1: gene penetrance 0.5 for heterozygous females, 0.8 for hemizygous males. Class 2: gene penetrance 1 for heterozygous females and hemizygous males. Healthy grandfathers are assumed to be obligate carriers. Affected subjects are assigned to class 2. available. In the second generation, no males but two females are affected: II. 2 walked late at between 2 and 3 years of age and had poor school performance. Her MRI shows a thin layer of heterotopic grey matter in both frontal lobes (fig 1B). The high resolution banding karyotype is normal, without deletion of 17p13.3. Clinical and radiological data are consistent with a forme fruste of SCLH. Her sister (II.7) has had epilepsy from infancy and mental retardation which required special education. She died aged 22 years during a status epilepticus. Although radiological investigations were not performed, the clinical phenotype was so typical that she was considered to be an affected female. Her blood sample was not available. In the third generation, three affected children out of five, two girls (III.1 and III.2) with SCLH and one boy (III.3) with lissencephaly, were born to the same mother (II.2) but to three different fathers (fig 1A). The first father (II.4) had a normal examination and his MRI showed no abnormality. The monozygotic twin brothers (III.4 and III.5) have normal MRI and neurological examination except for a mild speech development delay and one of them has hemiparesis. The affected son (III.3) fails to thrive, has seizures, and severe mental retardation. $\mathrm{He}$ is microcephalic without any visual contact, with marked hypotonia and pyramidal signs. The CT scan and the MRI show a smooth cortex with bilateral frontal agyria and pachygyria of the parietal, occipital, and temporal lobes (fig 1B). The karyotype is normal. The second father (II.3) is not known and his daughter (III.2) has mild psychomotor retardation, mainly in speech, epilepsy, and is hyperkinetic. Neurological examination shows pyramidal signs and drooling. She attended an institution for mild mentally retarded children. The 


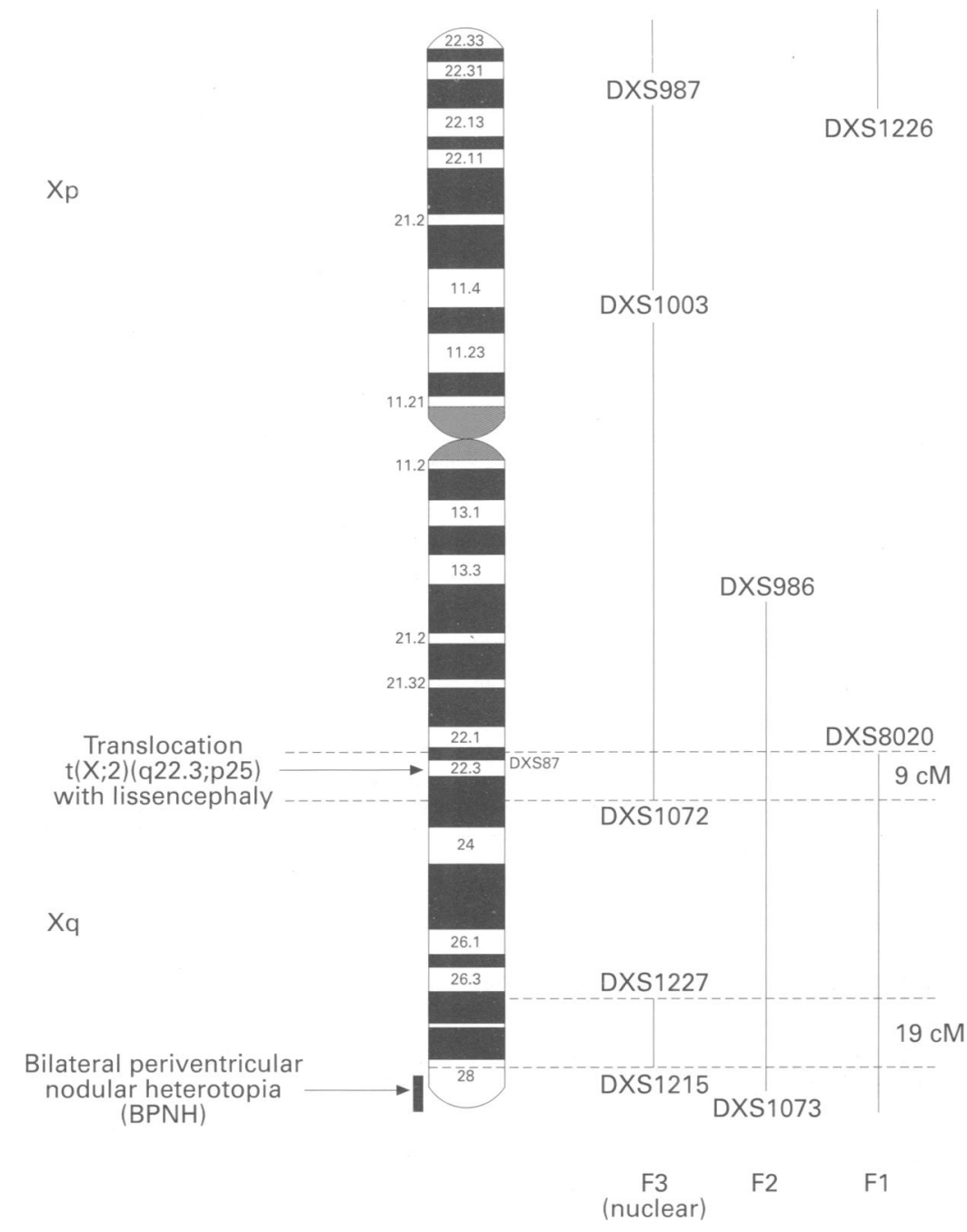

Figure 4 Exclusion mapping data corresponding to the three XSCLH/LIS families (F1, F2, and nuclear F3), taking into account the inheritance of the mutation from the grandfather in family 2. For each family, candidate intervals are represented by continuous lines flanked by the recombinant markers. Two intervals shared by the three families, in $X q 22.2-q 23$ and in Xq27, are limited by dotted lines. The position of the de novo $X$;autosomal translocation breakpoint $\left(t(X ; 2)(q 22 ; p 25)^{14}\right)$ and the candidate locus for bilateral periventricular nodular heterotopia (BPNH) syndrome ${ }^{13}$ are also indicated.

karyotype is normal. The MRI exhibits a band of heterotopia extending from the frontal to the parietal regions. The second daughter (III.1), conceived by artificial insemination with an unknown father, is mentally retarded with a global IQ of 66 . She requires special schooling. Neurological examination and karyotype are normal. MRI shows an abnormal cortex with an extended band of thick heterotopic grey matter (fig 1B).

Family 3

In family 3, two healthy males and seven females were born to apparently healthy parents. One female (II.3) has epilepsy and a mild weakness. The CT scan shows an image of SCLH. Her husband (II.2) has no neurological abnormality. The daughter (III.3), 7 years old, is microcephalic and has epilepsy. She is mentally retarded, hyperkinetic, and mildly ataxic. MRI shows extended and thick SCLH. Phenotype and MRI malformation are more severe in III. 3 than in her mother. The son (III.4), 5 years old, has axial hypotonia and spasticity of the limbs. $\mathrm{He}$ is bedridden with severe epilepsy (West syn- drome). He does not have any language. The CT scan shows agyria. The karyotypes of the children are normal. Another female (III.8), a cousin of the affected children, had neonatal convulsions without further epilepsy; she has limited intellectual function with speech retardation. MRI shows mild bilateral patchy lesions in the white matter and a left temporal lesion probably of acquired origin. Her healthy mother (II.10) has similar patchy lesions on MRI. Clinical and radiological data suggest that these two cases might correspond to a forme fruste of SCLH.

GENOTYPING

Blood was collected from the relatives indicated in the pedigrees (fig 1A). DNA was extracted by standard procedures. A total of 31 people were genotyped using 38 highly polymorphic Généthon microsatellite markers, ${ }^{17}{ }^{18}$ evenly distributed on the $\mathrm{X}$ chromosome (DXS1073, DXS1193, DXS8091, DXS998, DXS1215, DXS1200, DXS8028, DXS8084, DXS8073, DXS8106, DXS1227, DXS1062, DXS1047, DXS1001, DXS1220, DXS8081, DXS424, DXS8088, DXS1072, DXS1059, DXS1210, DXS1191, DXS1106, DXS8020, DXS990, DXS1196, DXS986, DXS1275, DXS991，DXS1003，DXS993，DXS1068, DXS1214, DXS989, DXS1226, DXS987, DXS1223, DXS996). PCR amplifications were performed as described by Gyapay et al. ${ }^{17}$ PCR amplification products were subjected to electrophoresis on a $6 \%$ denaturing polyacrylamide gel, transferred onto a nylon membrane, and then hybridised overnight at $42^{\circ} \mathrm{C}$ with $\left[{ }^{32} \mathrm{P}\right] \mathrm{dCTP}$ labelled poly-AC probes. DNA of CEPH subject No 1347 was included in each experiment as a control for allele size.

\section{LINKAGE ANALYSIS}

Two point disease to marker linkage analysis, maximum lod score calculation, and multipoint analysis were conducted with the MLINK, ILINK, and LINKMAP programs, ${ }^{19}$ respectively, using the software package FASTLINK (version 2.3P). ${ }^{20}$ The mutation rate and gene frequency were set at 0.001 and 0.0005 , respectively. The genetic distances used for multipoint analysis were as previously described. ${ }^{17} 18$

\section{Results}

\section{CLINICAL DATA}

Clinical homogeneity in the three families reported here was suggested on the following criteria. In each family, males are affected with lissencephaly, severe mental retardation, and epilepsy, while females have SCLH and mild mental impairment. Also, a common feature shared by families 2 and 3 is a worsening of the thickness of the heterotopic band and clinical phenotype in daughters compared with their mother. In family 2, II.2 has borderline intellectual function, no epilepsy, and subcortical laminar heterotopia localised in the frontal lobes. Unlike their mother, III. 1 and III. 2 have mental retardation and an extended band of thick heterotopic grey matter. In family 3 , in 
contrast to her mother, III.3 is mentally retarded, hyperkinetic, and microcephalic, with extended and thick SCLH.

In family 3 , in addition to these common features, atypical clinical and radiological features were observed in II.10 and III.8. Since these atypical forms are difficult to classify as true SCLH on the basis of available data generated by an extensive investigation, these subjects were not scored for linkage analysis and only the nuclear family F3 (subjects II.2, II.3, III.3, and III.4) was taken into account in the following results section. However, genotyping of the extended family 3 showed interesting data that will be discussed in the last section.

\section{LINKAGE DATA}

Thirty eight informative markers spanning the $\mathrm{X}$ chromosome were tested for exclusion mapping. Almost the whole $\mathrm{X}$ chromosome was excluded, except two intervals shared by the three families, in Xq22.2-q23 and in Xq27. Results of a two point linkage analysis, achieved on unambiguous subjects with full penetrance for heterozygous females and hemizygous males, indicated potential linkage between the disease and marker DXS1059 in $\mathrm{Xq} 22.3$ with a lod score $Z=2.11$ at $\theta=0$, above the critical value $Z=2$ that is considered as significant for a candidate chromosome ${ }^{21}$ (table 1). Flanking markers DXS8020 in Xq22.2 and DXS1072 in Xq23 defined a $9.2 \mathrm{cM}$ candidate region. Another positive, but non-significant lod score was found for marker DXS8084 $(\mathrm{Z}=1.45, \theta=0)$ in Xq27. However, haplotype analysis of families 2 and 3 indicates that at the candidate $\mathrm{Xq} 22$ region and also at $\mathrm{Xq} 27$, all affected children share alleles inherited from their healthy grandfather (fig 1A). Indeed, using multipoint linkage analysis, we observe a dramatic decrease of the maximum lod score at DXS1059 ( $\mathrm{Z}=1.1$ at $\theta=0)$ and the $\mathrm{Xq} 27$ region was ruled out (fig 2 , first linkage analysis).

To take into account the inheritance of the healthy grandfather's , haplotype by affected children, a second lod score calculation was performed assuming I. 1 in family 2 to be an obligate carrier. The results of the second two point linkage analysis (table 1 and exclusion map in fig 4) show a potential but nonsignificant linkage between the disease and two regions in $\mathrm{Xq} 22(\mathrm{Z}=1.75, \theta=0$ at $\mathrm{DXS1191)}$ and $\mathrm{Xq} 27$ ( $Z=1.81, \theta=0$ at DXS8106). In contrast to the first linkage analysis, in this mode of inheritance the multipoint lod score analysis showed compatible results with the two point lod score values (fig 2 , second linkage analysis). The contribution of families 1 and 3 to the lod score value is not influenced by the mode of inheritance of the mutation However, the loss of two informative meioses in family 2 , since males II. 5 and II. 8 cannot inherit their father's $\mathrm{X}$ chromosome, led to a moderate decrease in two point lod score in Xq22.3 ( $\mathrm{Z}=2.11$ to $\mathrm{Z}=1.75$ ) and an enlargement of the interval in $\mathrm{Xq} 27$ with respect to the first linkage analysis (table 1).

\section{Discussion}

XSCLH/LIS syndrome represents a distinct and original $\mathrm{X}$ linked cortical dysgenesis involving early embryonic neuronal migration mechanisms. ${ }^{14}$ The common genetic origin of SCLH and lissencephaly and evidence of X linked inheritance has already been strongly suggested in five striking observations ${ }^{4}{ }^{14} 22$ : (1) the greatly predominant occurrence of sporadic SCLH in females, ${ }^{16}{ }^{16}$ (2) in familial forms, only males exhibit major brain malformations with lissencephaly and females express exclusively mild phenotypes with SCLH, (3) in family 2, a woman with SCLH has two daughters with SCLH and a son with lissencephaly, each by a different father, (4) no male to male transmission has ever been described, (5) a girl described by Dobyns et al had lissencephaly and a de novo $\mathrm{X} ; 2$ translocation. If we hypothesise that lissencephaly observed in hemizygous males results from the absence of the functioning gene in all cells and SCLH observed in females results from mosaicism related to the random inactivation of the $X$ chromosomes, the unusually severe phenotype (lissencephaly) associated with this translocation could result from the non-random inactivation of the normal $\mathrm{X}$ chromosome, therefore leading to complete inactivation of both alleles in most cells.

The preliminary molecular study ${ }^{14}$ of this apparently balanced, de novo, $\mathrm{X}$;autosome translocation, 46,XX,t (X;2) (q22;p25), showed that the breakpoint is distal to marker DXS87 (fig 3), which suggested a localisation of the XSCLH/LIS gene at Xq22.3. Here we report an exclusion mapping study performed on a homogeneous population of families with XSCLH/LIS syndrome. Our results showed a potential location of the XSCLH/LIS locus either in Xq22.3-q23, between DXS8020 and DXS1072, or in Xq27 (figs 2 and 4). Though the latter region was not excluded, the compatibility between the mapping of the breakpoint involved in the $\mathrm{X} ; 2$ balanced translocation (fig 4) and the interval of assignment in Xq22 strongly suggests that the region defined within $\mathrm{Xq} 22.3-\mathrm{q} 23$ is the likely locus for XSCLH/ LIS.

The absence of overlap between the regions defined in this study and the recently reported locus in Xq28 (interval of $7 \mathrm{cM}$ between DXS1113 and the telomere) for bilateral periventricular nodular heterotopia (BPNH) syndrome $^{13}$ enabled us to rule out that these two $\mathrm{X}$ linked cortical malformations are allelic forms of the same gene (fig 4).

Haplotype analysis of family 2 and nuclear family 3 indicates that at the candidate region $\mathrm{Xq} 22.3-23$ and also in Xq27 all affected children share alleles inherited from their healthy grandfather (fig 1A). Paternal origin of the mutation is also suggested in two pedigrees of $\mathrm{X}$ linked dominant pachygyria in males with decreased penetrance and expressivity in carrier females reported by Berry-Kravis et $a l^{3}$ and Zollino et al. ${ }^{24}$ In these families, there is no affected male but only affected or transmitting females in the second generation. Although the number of families with XSCLH/LIS does not 
allow reliable statistical analysis of this striking observation, we believe, in view of the data reported here, that it is reasonable to raise the hypothesis of a skewed origin of de novo mutations or mosaicism, occurring in male germline cells. A much higher rate of de novo germline mutations in males than in females was also recently suggested by Thomas ${ }^{25}$ as a genetic basis for $\mathrm{X}$ linked dominant disorders with lethality or a very severe phenotype in males. This explanation is in line with the skewing of the sex ratio $(3 / 48)$ of male to female patients with sporadic subcortical laminar heterotopia ${ }^{14}$ and the absence of affected males in the second generation of XSCLH/LIS familial cases: mutations occur in fathers' germline cells and are transmitted only to their daughters.

A second way to explain the unexpected transmission by healthy transmitting males, essentially in family 2 , is a "dynamic mutation" 26 which involves a two step premutation/ mutation mechanism, inspired by the mode of inheritance of the fragile X syndrome. ${ }^{27}{ }^{28}$ The application of this model to XSCLH/LIS syndrome would also integrate the notable worsening of phenotype in females across generations in families 2 and 3. Although a skewed inactivation of the $\mathrm{X}$ chromosomes cannot be ruled out, this latter phenomenon can hardly explain this striking worsening of the daughters' phenotype with respect to their mother. It is interesting to point out that either one of the two hypotheses, male germline mosaicism or dynamic mutation, could reliably be used to explain the segration of the disease in the extended family 3 , including the two atypical forms of SCLH observed in II.10 and III.8, and the inheritance of the abnormal chromosome in the healthy boy III.2 (fig 1A). To evaluate the linkage between the disease and markers of the $\mathrm{X}$ chromosome, taking into account the extended family 3 together with the other two families, we have proposed a linkage analysis model with incomplete penetrance and healthy transmitting males (see legend to fig 3 ). This model could be applied to the study of segregation of germline mosaicism mutations as well as dynamic mutations. Two point lod scores obtained with this genetic model showed a significant linkage between XSCLH/LIS and DXS1059 with a maximum lod score $Z=2.67$ at $\theta=0$ and excluded linkage with Xq27 markers. Compilations of five multipoint location score analyses carried out with 11 informative markers are concordant with two point lod score data (fig 2, third linkage).

Investigation of more families and further linkage studies should allow the genetic interval to be refined, and identification of the gene will elucidate underlying molecular and genetic mechanisms involved in this fascinating cortical dysgenesis.

We thank members of the families for their participation in this study. We are grateful to Dr I L Mandel for his useful comments study. We are grateful to Dr $\mathrm{L}$ Mandel for his useful comments
on the manuscript. The authors wish to thank Drs Prudhomme,
Gabor Gyapay, Jean Weissenbach, and coworkers for the use of Genethon's facilities for lymphoblastoid cells cultures and DNA extraction. This work was supported in part by grants from extraction. This work was supported in part by grants from (INSERM) and the Association Française contre les Myopa(INSERM)

1 Raymond A, Fish D, Sisodiya S, Alsanjari N, Stevens J Shorvon S. Abnormalities of gyration, heterotopias, tuberShorvon $S$. Abnormalities of gyration, heterotopias, tuber-
ous sclerosis, focal cortical dysplasia, microdysgenesis, dysous sclerosis, focal cortical dysplasia, microdysgenesis, dys-
embryoplastic neuroepithelial tumor and dysgenesis of the archicortex in epilepsy. Clinical, EEG and neuroimaging features in 100 adults patients. Brain 1995;118:629-60.

2 Palmini A, Andermann F, Aicardi J, et al. Diffuse cortica dysplasia, or the "double cortex" syndrome : the clinical and epileptic spectrum in 10 patients. Neurology 1991;41 $1656-62$

3 Barkovich A, Guerrini R, Battaglia G, et al. Band heterotopia: correlation of outcome with magnetic resonance imaging parameters. Ann Neurol 1994;36:609-17.

4 Pinard JM, Motte J, Chiron C, Brian R, Andermann E Dulac O. Subcortical laminar heterotopia and lissenDulac O. Subcortical laminar heterotopia and lissencephaly in two families: a single X linked dom

Neurol Neurosurg Psychiatry 1994;57:914-20.
Franzoni E, Bernardi B, Marchiarni V, Crisanti A, Marchi 5 Franzoni E, Bernardi B, Marchiarni V, Crisanti A, March
R, Fonda C. Band brain heterotopia. Case report and literature review. Neuropediatrics 1995;26:37-40.

6 Aicardi J. The agyria-pachygyria complex: a spectrum of cortical malformations. Brain Dev 1991;13:1-8.

7 Dobyns W, Elias E, Newlin A, Pagon R, Ledbetter D. Causal heterogeneity in isolated lissencephaly. Neurology 1992;42: 1375-88.

8 Pagon R, Clarren S, Millam D, Hendrickson A. Autosomal recessive eye and brain anomalies: Warburg syndrome. $\mathcal{F}$ Pediatr 1983;102:542-6.

9 Reiner O, Carrozzo R, Shen Y, et al. Isolation of a Miller-Dieker lissencephaly gene containing $G$ protein b-subunit-like repeats. Nature 1993;364:717-21

10 Ledbetter S, Kuwano A, Dobyns W, Ledbetter D. Microdeletions of chromosome $17 \mathrm{p} 13$ as a cause of isolated lissencephaly. Am F Hum Genet 1992;50:182-9.

11 Huttenlocher P, Taravath S, Mojtahedi S. Periventricular heterotopia and epilepsy. Neurology 1994;44:51-5.

12 DiMario F, Cobb R, Ramsby G, Leicher C. Familial band heterotopias simulating tuberous sclerosis. Neurology 1993; 43:1424-6.

13 Eksioglu Y, Scheffer I, Cardenas P, et al. Periventricula heterotopia: an X-linked dominant epilepsy locus causing aberrant cerebral cortical development. Neuron 1996;16: 77-87.

14 Dobyns W, Andermann E, Andermann F, et al. X-linked malformations of neuronal migration. Neurology (in press).

15 Pinard JM, Desguerre I, Motte J, Dulac O, Ponsot G. Hétérotopies laminaires sous-corticales et lissencéphalie: malformations cérébrales d'origine familiale commune, liée à l'X. Rev Neurol 1995;151:171-6.

16 Pinard JM. Subcortical laminar heterotopia and other $\mathrm{X}$-linked cerebral cortical dysgenesis. In: Arzimanoglou A Goutières F, eds. Trends in child neurology. Paris: John LibGoutières F, eds. Trenc

17 Gyapay G, Morissette J, Vignal A, et al. The 1993-94 Généthon human genetic linkage map. Nat Genet 1994;7:246 339

18 Dib C, Fauré S, Fizames C, et al. A comprehensive genetic map of the human genome based on 5.264 microsatellites. Nature 1996;380:152-4.

19 Lathrop GM, Lalouel JM. Easy calculations of lod scores and genetic risks on small computers? Am 7 Hum Genet 1984;37:482-98.

20 Cottingham RW, Idury RM, Schaffer A. Faster sequential genetic linkage computations. Am $\mathcal{f}$ Hum Genet 1993;53 252-63.

21 Ott J. Analysis of human genetic linkage. Revised edition. Baltimore: Johns Hopkins University Press, 1991.

22 Livingston J, Aicardi J. Unusual MRI appearance of diffuse subcortical heterotopia or "double cortex" in two children. f Neurol Neurosurg Psychiatry 1990;53:617-20.

23 Berry-Kravis E, Israel J. X-linked pachygyria and agenesis of the corpus callosum: evidence for an $\mathrm{X}$ chromosome lissencephaly locus. Ann Neurol 1994;36:229-33.

24 Zollino M, Mastroiacovo P, Zampino G, Mariotti P, Neri G. New XLMR syndrome with characteristic face, hypogenitalism, congenital hypotonia and pachygyria. $\mathrm{Am} \mathcal{f} \mathrm{Med}$ Genet 1992;43:452-7.

25 Thomas G. High male:female ratio of germ-line mutations: an alternative explanation for postulated gestational an alternative explanation for postulated gestational Hum Genet 1996;58:1364-8.

26 Richard R, Sutherland GR. Heritable unstable DNA sequences. Nat Genet 1992;1:7-9.

27 Sherman S, Jacobs P, Morton N, et al. Further segregation analysis of the fragile $\mathrm{X}$ syndrome with special reference to analysis of the fragile X syndrome with special refe
transmitting males. Hum Genet 1985;69:289-99.

28 Oberlé I, Rousseau F, Heitz D, et al. Instability of a 550-base pair DNA segment and abnormal methylation in fragile X syndrome. Science 1991;252:1097-102. 